\title{
Acute ICA occlusion due to pituitary apoplexy resulting In Internal Carotid Artery Occlusion and Stroke: Case Report, Review of The Literature, and Treatment Rationale
}

\author{
Monday N Igwe*, Muideen O Bakare, Ahamefule O Agomoh, Gabriel M Onyeama \\ Department of Psychological Medicine, Nigeria. \\ *Corresponding Author :Monday N Igwe, Department of Psychology, Mayo Clinic, Rochester, Minnesota, USA, \\ E-mail: mondayigwe@yahoo.com
}

Received date: March 03,2017 ;Accepted date: March 16,2017; Published date: March 29,2017.

Citation for this Article: Monday N Igwe, Acute ICA occlusion due to pituitary apoplexy resulting In Internal Carotid Artery Occlusion and Stroke: Case Report, Review of The Literature, and Treatment Rationale, J Psychology and Mental Health Care . Doi: 10.31579/2637-8892/002

Copyright : (C) 2017 Monday N Igwe. This is an open-access article distributed under the terms of The Creative Commons Attribution License, which permits unrestricted use, distribution, and reproduction in any medium, provided the original author and source are credited.

\begin{abstract}
We report the case of a 63 year-old man who presented with sudden-onset, severe headache. Work-up revealed a hemorrhagic pituit macroadenoma. He then suffered sudden-onset aphasia and right hemiparesis. Further evaluation revealed left ICA occlusion. Emerg transsphenoidal resection of the tumor produced recanalization of the occluded ICA, but his neurological symptoms persisted. ICA occlus following pituitary tumor apoplexy is a rare event that must be recognized early for optimal patient outcomes. We report the first case $n$ demonstration of carotid recanalization after tumor resection, review the incidence of ICA occlusion due to pituitary tumors, describe the poss mechanisms, and recommend optimal treatment strategies.

Keywords

Pituitary Macroadenoma; Apoplexy; Internal Carotid Artery Occlusion; Transsphenoidal Surgery; Recanalization
\end{abstract}

\section{Introduction}

Pituitary tumor apoplexy, a potential endocrinological and neurosurgical emergency, results from infarction or spontaneous hemorrhage of a pituitary adenoma. It is characterized by the sudden onset of headache, visual loss, ophthalmoplegia, and possible loss of consciousness. Due to the pituitary's anatomical location in the sella turica and proximity to the cavernous sinus, compression of perisellar structures such as the adjacent cranial nerves and internal carotid artery (ICA) is possible. Cerebral infarction due to compression and occlusion of the ICA, however, is very rare. In this case report, we present a case of a pituitary tumor apoplexy with subsequent ICA occlusion that was reversed after transphenoidal tumor resection.

\section{Case Report}

A 63 year-old man presented to an outside hospital emergency room with a complaint of sudden-onset, severe headache. He had no other symptoms and denied visual changes. He had a past medical history of hypertension, diabetes, and asthma. A CT of the head revealed a heterogeneous, hyperdense, sellar-suprasellar lesion with expansion of the sella turcica and erosion of the dorsum sellae with no cortical changes (Figure 1A). Routine laboratory studies were initiated and the patient received stress-dose corticosteroids. After two hours in the ER, the patient suffered sudden-onset of aphasia and right-sided hemiplegia. His vital signs remained unchanged (MAP 105-116) and repeat CT was unchanged as well. CT angiography revealed complete occlusion of the left internal carotid artery from its origin to the clinoidal segment (Figure 1B). The patient was then transferred to our institution for further management. On arrival he was awake and alert opening his eyes spontaneously. He was able to follow simple commands but could not generate any speech other than counting to three.
He had leftward eye deviation and right lower facial weakness, and a right hemiplegia.

He was taken for immediate MRI which further demonstrated the hemorrhagic pituitary macroadenoma with suprasellar extension and extensive expansion into the cavernous sinus, left greater than right, without overt invasion. There were also acute infarctions seen in the left cerebral hemisphere (Figure 2). The patient was then taken emergently to the operating room for endoscopic transsphenoidal resection of the pituitary tumor, approximately six hours after the onset of aphasia and weakness. The operation was unremarkable; tumor and blood products were encountered under high pressure and removed without difficulty. Inspection of the diaphragma sellae and the medial walls of the cavernous sinus with an angled endoscopic lens showed no cavernous sinus invasion and a gross total resection was achieved. Intraopertive microdoppler signals revealed flow in the cavernous ICA. Postoperatively, the patient's neurological status remained unchanged: his aphasia and right hemiplegia persisted. His postop MRI with MRA showed gross total resection of the tumor with recanalization of the left ICA (Figure 3), but progression of infarctions in the left cerebral hemisphere. He required placement of a feeding tube and was discharged to a skilled nursing facility 12 days after his operation. Pathology reported typical pituitary adenoma with hemorrhage and early necrosis. His neurological status remained unchanged and he was without recurrence of tumor on imaging three months postop. The patient expired six months after surgery from complications of pneumonia. 


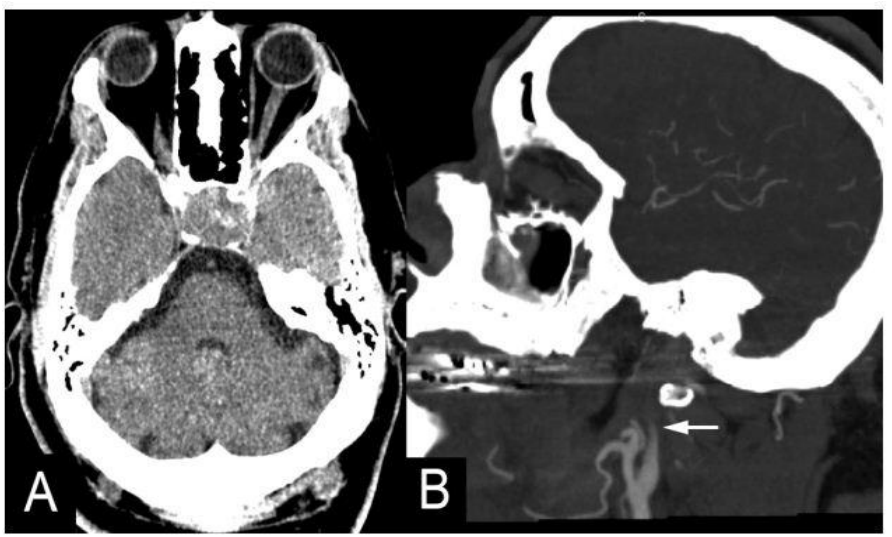

Figure 1: Initial CT head through sella turcica (A) showing hyperdense soft tissue lesion within the sella with erosion and expansion of dorsum sellae. CT angiogram (B) shows occlusion of left ICA just beyond its origin (arrow).

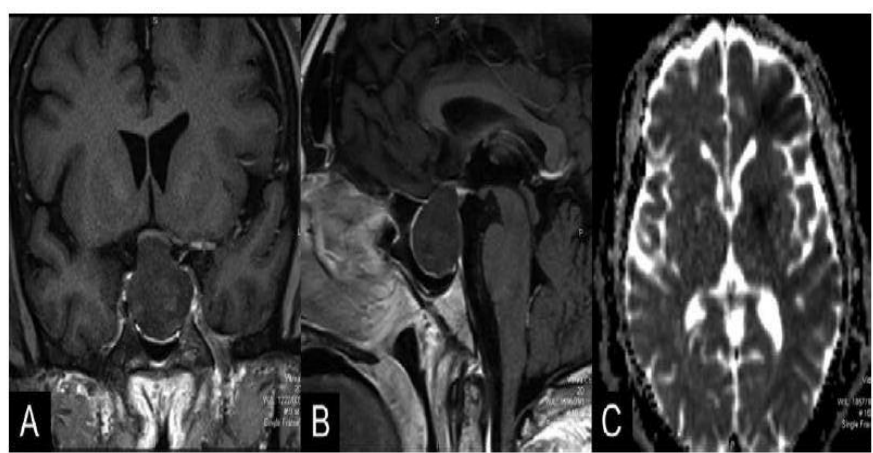

Figure 2: Preoperative MRI of brain and sella turcica with coronal (A) and sagital (B) post-contrast T1 images demonstrating heterogeneous tumor within the sella with suprasellar extension and expansion of the lateral walls of the sella. Diffusion-weighted images (C) show left frontal cortical and subcortical acute ischemic changes.

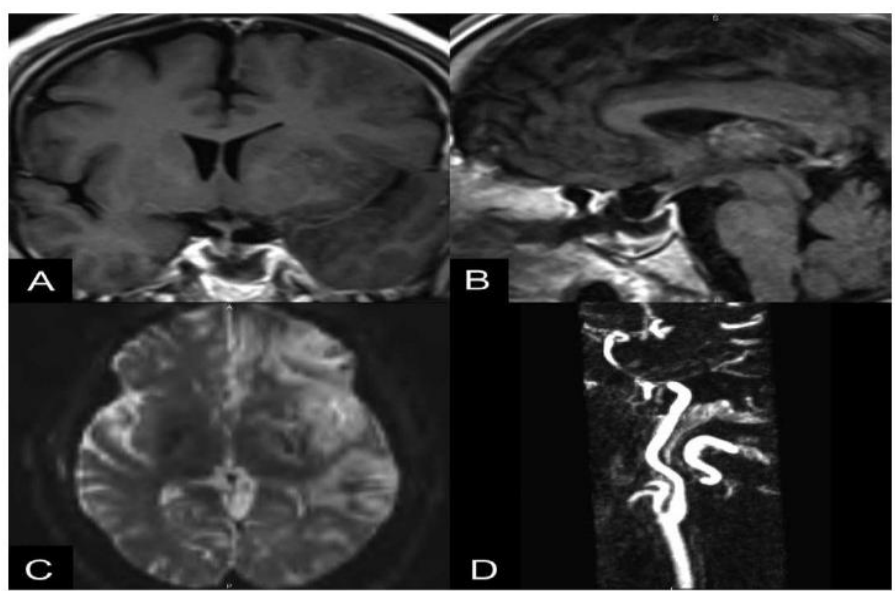

Figure 3: Postoperative MR images. Coronal (A) and sagital (B) post-contrast $\mathrm{T} 1$ images demonstrate gross total resection of the tumor and decompression of the walls of the sella. Diffusion-weighted imaging shows progression of ischemic changes. MR angiogram of the left ICA (D) shows restoration of flow from origin to cranial base.

\section{Discussion}

Pituitary tumor apoplexy is the infarction-whether by ischemic or hemorrhagic means - of a preexisting pituitary adenoma leading to rapid expansion and endocrine failure of the gland. In an analysis of surgically resected pituitary adenomas, up to $10 \%$ of specimens showed evidence of pituitary tumor apoplexy, many of which were incidental findings and clinically insignificant [1]. Apoplexy is clinically typified as presenting with sudden onset of headache, visual loss, oculomotor weakness, and Addisonian crisis.
Compromised cerebral blood flow following pituitary apoplexy is a rare occurrence. In this scenario, cerebral infarction can occur secondary to vasospasm or mechanical compression of the cavernous ICA [2-12]. Mechanical compression of the ICA would require intrasellar pressure (ISP) to surpass the mean arterial pressure (MAP). In a study of ISP in patients with pituitary apoplexy, rapid rise in pressure was documented with a median value of $47 \mathrm{mmHg}$ (range $25-58 \mathrm{mmHg}$ ) [13]. Moreover, systemic hypotension due to hypothalamic involvement and/or pituitary dysfunction leads to a drop in MAP which can exacerbate any mechanical compression of the ICA. Conversely, relief of elevated ISP with surgical decompression can relieve arterial compression, allowing for restoration of cerebral blood flow as demonstrated in our case and others. Additionally, hypertensive therapy may be initiated as a temporary treatment and a bridge to surgical decompression.

Early diagnosis and intervention is the key to treating patients presenting with cerebral ischemia and imaging consistent with a pituitary apoplexy. Both the stroke and the pituitary apoplexy must be recognized quickly and appropriate medical management and imaging must be performed promptly. Failure to recognize a hemorrhagic pituitary tumor in this setting could lead to the use of thrombolytic medications which could exacerbate the hemorrhage and increase morbidity, likely delaying surgical intervention. The diagnosis of apoplexy can be made with routine head CT, and confirmed with MRI if time permits. Diagnosing ICA occlusion requires a vascular study, and CTA or MRA of the head and neck can be performed concurrently with brain imaging. Once apoplexy has been established, patients should be treated with stress-dose corticosteroids followed by urgent decompression of both the optic apparatus and ICA.

The goal in treatment of cerebral ischemia is rapid reperfusion to reduce tissue death and further neurological deficit and avoid the risk of hemorrhagic conversion. Although no absolute "time window" has been defined for reperfusion after ICA occlusion [14], rapid recanalization of the occluded vessel is recommended for improved patient outcome. Therefore, endoscopic or open surgical intervention with the intent to revascularize the ischemic territory by decompression is more likely to be beneficial if performed as quickly as possible. In the case presented, the patient was decompressed within six hours of onset of his stroke symptoms, but still failed to achieve a clinical recovery despite radiographic evidence of restoration of flow in the affected ICA.

Appropriate imaging must therefore be performed promptly to recognize the apoplexy and the patient must undergo immediate decompression to optimize neurological outcome. This may require treatment in a tertiary care center where experienced multidisciplinary specialists are available around the clock for diagnosis, surgical treatment, and postoperative critical care.

\section{Conclusion}

We have presented a case of acute ICA occlusion due to pituitary apoplexy. The diagnosis was made promptly and the patient was decompressed within six hours of his ictus. He had return of flow in his ICA postoperatively but failed to show neurological improvement. Although exceptionally rare, apoplexy as a cause of ischemic stroke should be considered, especially in patients presenting with sudden-onset headache, vision changes, or signs of hypocortisolemia. We therefore recommend maintenance of a high index of suspicion, prompt radiographic diagnosis, and urgent surgical decompression in these patients.

\section{References}

1. Weis-Müller BT, Huber R, Spivak-Dats A, Turowski B, Siebler M, et al. (2008) Symptomatic acute occlusion of the internal carotid artery: reappraisal of urgent vascular reconstruction based on current stroke imaging. J Vasc Surg 47: 752-759.

2. Chokyu I, Tsuyuguchi N, Goto T, Chokyu K, Chokyu M, et al. (2011) Pituitary apoplexy causing internal carotid artery occlusion-case report. Neurol Med Chir (Tokyo) 51: 48-51. 
3. Schnitker MT, Lehnert HB (1952) Apoplexy in a pituitary chromophobe adenoma producing the syndrome of middle cerebral artery thrombosis; case report. J Neurosurg 9: 210-213.

4. Sakalas R, David RB, Vines FS, Becker DP (1973) Pituitary apoplexy in a child. Case report. Journal of neurosurgery 39: 519522.

5. Rosenbaum TJ, Houser OW, Laws ER (1977) Pituitary apoplexy producing internal carotid artery occlusion. Case report. J Neurosurg 47: 599-604.

6. Majchrzak H, Wencel T, Dragan T, Bialas J (1983) Acute hemorrhage into pituitary adenoma with SAH and anterior cerebral artery occlusion. Case report. J Neurosurg 58: 771-773.

7. Bernstein M, Hegele RA, Gentili F, Brothers M, Holgate R, et al. (1984) Pituitary apoplexy associated with a triple bolus test. Case report. J Neurosurg 61: 586-590.

8. Clark JD, Freer CE, Wheatley T (1987) Pituitary apoplexy: an unusual cause of stroke. Clinical radiology. 38: 75-77.

9. Lath R, Rajshekhar V (2001) Massive cerebral infarction as a feature of pituitary apoplexy. Neurol India 49: 191-193.
10. Yang SH, Lee KS, Lee KY, Lee SW, Hong YK (2008) Pituitary apoplexy producing internal carotid artery compression: a case report. J Korean Med Sci 23: 1113-1117.

11. Dogan S, Kocaeli H, Abas F, Korfali E (2008) Pituitary apoplexy as a cause of internal carotid artery occlusion. Journal of clinical neuroscience : official journal of the Neurosurgical Society of Australasia 15: 480-483.

12. Alentorn A, Bruna J, Acebes JJ, Velasco R (2011) Stroke and carotid occlusion by giant non-hemorrhagic pituitary adenoma. Acta Neurochir (Wien) 153: 2457-2459.

13. Zayour DH, Selman WR, Arafah BM (2004) Extreme elevation of intrasellar pressure in patients with pituitary tumor apoplexy: relation to pituitary function. J Clin Endocrinol Metab 89: 5649-5654.

14. Hesselmann V, Niederstadt T, Dziewas R, Ritter M, Kemmling A, et al. (2012) Reperfusion by combined thrombolysis and mechanical thrombectomy in acute stroke: effect of collateralization, mismatch, and time to and grade of recanalization on clinical and tissue outcome. AJNR Am J Neuroradiol 33: 336-342. 